\title{
BMJ
}

\section{Patient level pooled analysis of 68500 patients from seven major vitamin D fracture trials in US and Europe}

\author{
The DIPART (vitamin D Individual Patient Analysis of Randomized Trials) Group
}

Correspondence to: B Abrahamsen, Department of Internal Medicine and Endocrinology, Copenhagen University Hospital Gentofte, Niels Andersensvej 65, DK-2900 Hellerup, Denmark

b.abrahamsen@physician.dk

Cite this as: BMJ 2010;340:b5463 doi:10.1136/bmj.b5463

\section{ABSTRACT}

Objectives To identify participants' characteristics that influence the anti-fracture efficacy of vitamin D or vitamin D plus calcium with respect to any fracture, hip fracture, and clinical vertebral fracture and to assess the influence of dosing regimens and co-administration of calcium. Design Individual patient data analysis using pooled data from randomised trials.

Data sources Seven major randomised trials of vitamin D with calcium or vitamin D alone, yielding a total of 68517 participants (mean age 69.9 years, range $47-107$ years, $14.7 \%$ men).

Study selection Studies included were randomised studies with at least one intervention arm in which vitamin $D$ was given, fracture as an outcome, and at least 1000 participants.

Data synthesis Logistic regression analysis was used to identify significant interaction terms, followed by Cox's proportional hazards models incorporating age, sex, fracture history, and hormone therapy and bisphosphonate use.

Results Trials using vitamin D with calcium showed a reduced overall risk of fracture (hazard ratio 0.92, 95\% confidence interval 0.86 to $0.99, \mathrm{P}=0.025$ ) and hip fracture (all studies: $0.84,0.70$ to $1.01, \mathrm{P}=0.07$; studies using $10 \mu \mathrm{g}$ of vitamin D given with calcium: $0.74,0.60$ to $0.91, P=0.005)$. For vitamin $\mathrm{D}$ alone in daily doses of $10 \mu \mathrm{g}$ or $20 \mu \mathrm{g}$, no significant effects were found. No interaction was found between fracture history and treatment response, nor any interaction with age, sex, or hormone replacement therapy.

Conclusion This individual patient data analysis indicates that vitamin D given alone in doses of $10-20 \mu \mathrm{g}$ is not effective in preventing fractures. By contrast, calcium and vitamin $\mathrm{D}$ given together reduce hip fractures and total fractures, and probably vertebral fractures, irrespective of age, sex, or previous fractures.

\section{INTRODUCTION}

Fragility fractures cause excess mortality, substantial morbidity, and related health and social service expenditures in older people. ${ }^{12}$ Risk of fracture is higher in institutionalised older people than in community dwelling older people of the same age, reflecting a greater risk of falls and lower bone mineral density. ${ }^{34}$ Vitamin D insufficiency is common in older people, particularly in residential and care homes. This may contribute to secondary hyperparathyroidism, bone loss, impaired neuromuscular function, and an increased risk of falls and fractures. ${ }^{5-8}$ This provides the rationale for using vitamin $\mathrm{D}$ to prevent fractures in older people.

A large randomised controlled trial in women in French nursing homes or apartments for older people showed that calcium and vitamin D supplementation increased serum 25-hydroxyvitamin D, decreased parathyroid hormone, improved bone density, and decreased hip fractures and other non-vertebral fractures. ${ }^{9}$ Subsequent randomised trials examining the effect of vitamin D supplementation - with or without calcium-on the incidence of fractures have produced conflicting results. ${ }^{10}$ A meta-analysis in 2005 suggested that $17.5-20 \mu \mathrm{g}$ of vitamin $\mathrm{D}$ daily decreased the risk of hip and non-vertebral fractures, whereas lower doses $\left(10 \mu \mathrm{g} /\right.$ day) were ineffective. ${ }^{11}$ However, recent meta-analyses indicate that a combination of calcium and vitamin D reduces hip and non-vertebral fractures but that vitamin $\mathrm{D}$ alone does not. ${ }^{12} 13$

Study level meta-analyses may be adequate when estimating a singled pooled treatment effect or investigating study level characteristics, but they can lead to biased assessments and have limitations in explaining heterogeneity. ${ }^{14}$ Analyses of individual patients' data offer improved statistical power to investigate whether treatment effects are related to the patient. We used individual patient data methods to do a meta-analysis of randomised controlled trials of vitamin $\mathrm{D}$ - with or without calcium - in preventing fractures and investigated if treatment effects are influenced by patients' characteristics.

\section{METHODS}

\section{Searching and selection criteria}

We searched, with no language restrictions, for publications between January 1966 and July 2008 in Medline, Embase, and the Cochrane Central Register of Controlled Trials by using MeSH terms: [Fractures, bone] combined with [Vitamin D], [Ergocalciferol] or [Cholecalciferol]. We also searched for text words in title and abstract: "Fractu*" or "Bone fractu*", in combination with "Vitamin D", "Cholecalciferol", or "Colecalciferol". We included studies if they were 
randomised (individual or cluster), had at least one intervention arm in which vitamin $\mathrm{D}$ was given and one arm without vitamin $\mathrm{D}$, used fracture as an outcome, and included at least 1000 patients. The decision to include only studies above this size was driven by concerns that each study, while contributing additional cases, would also further reduce the mass of shared study variables for aggregated analysis. We identified 248 abstracts (fig 1); 47 covered clinical trials of vitamin $\mathrm{D}$ with a fracture outcome -36 with $\mathrm{n}<1000$ and 11 with $\mathrm{n} \geq 1000$. We contacted the corresponding authors of these 11 trials. Four groups were unwilling or unable to provide patient level data. ${ }^{915-17}$ Seven groups agreed to participate.

\section{Included studies}

Six studies were individually randomised. ${ }^{18-23}$ One study was cluster randomised at the level of home care district. ${ }^{24}$ Of the individually randomised controlled trials, one was quasi-randomised by birth date. ${ }^{19}$ Two studies used a factorial design. ${ }^{2224}$ Table 1 gives the details of the studies. Information on fracture history was not available in one study. ${ }^{18}$ All studies reported incident hip fractures and other non-vertebral fractures. All but one reported on clinical vertebral fractures. ${ }^{19}$

\section{Data extraction and validation}

We defined a standardised data format and retrieved datasets electronically in anonymised form from the corresponding authors. We issued queries to the participating centres for discordant data.

\section{Quantitative data synthesis and statistical analysis}

We analysed data at the level of the patient and according to the intention to treat principle. The timescale used was number of days between date of randomisation and date of fracture. When the fracture date was unknown, we used the date of the reporting visit. The primary end point was any fracture, with hip fracture

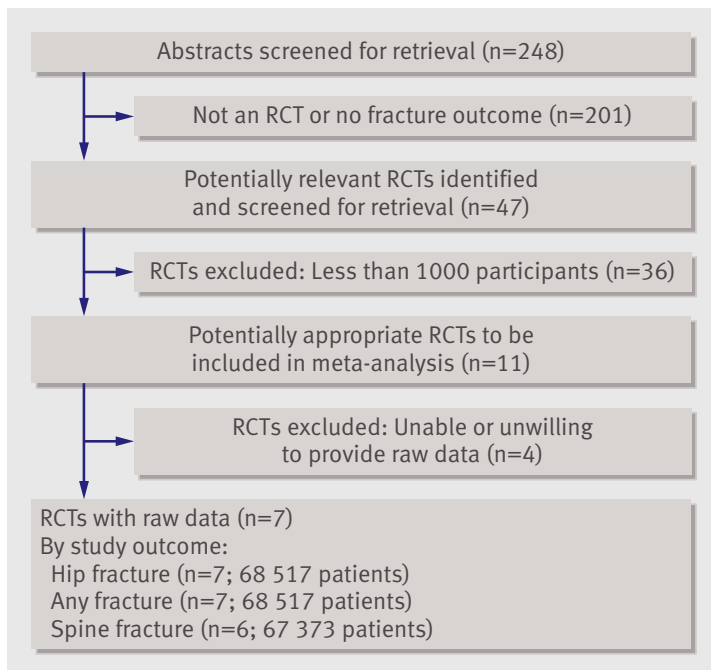

Fig 1| Flow chart of analysis. RCT=randomised controlled trial and clinical vertebral fracture as secondary end points. We defined base models by using conditional logistic regression incorporating known predictors of fracture risk, which would be expected a priori to contribute to variation in fracture rates: age, sex, hormone replacement therapy, bisphosphonates, previous hip fracture, previous vertebral fracture, and "other previous fracture" in adulthood. We added treatment allocation and interaction terms to this model to identify factors that significantly modified the response to vitamin D. We pre-specified the following study level variables for entry into this interaction analysis: vitamin $\mathrm{D}$ daily dose equivalent, route (oral or intramuscular), and co-administration of calcium. We then used variables that interacted significantly to stratify the subsequent fixed effects Cox fracture-free survival analysis, which contained a series of dummy variables to capture residual differences in risk of fracture between trials. A subgroup analysis by dose $(10 \mu \mathrm{g} /$ day $v 20 \mu \mathrm{g}$ /day) was pre-specified. We thus classified the Meyer, Larsen, and Women's Health Initiative (WHI) studies as $10 \mu \mathrm{g}$ studies and classified the Smith study (equivalent to $20.5 \mu \mathrm{g} /$ day), the Lyons study, the RECORD study, and the Porthouse study (all equivalent to $20 \mu \mathrm{g} /$ day) as $20 \mu \mathrm{g}$ studies. Observations were truncated after 36 months; only the WHI study provided sufficient patients to populate the analysis beyond this.

\section{Sensitivity}

We did an influence analysis to assess to what extent conclusions would have been modified by failure to include one or more individual studies in the analysis. Recent work suggests that ergocalciferol has half the calciotrophic effect of cholecalciferol, ${ }^{25}$ so we regrouped $20 \mu \mathrm{g}$ ergocalciferol studies with $10 \mu \mathrm{g}$ cholecalciferol studies.

\section{RESULTS}

Base model including previous fractures (six studies, $\mathrm{n}=65073$ )

Increasing age (hazard ratio per decade $1.34,95 \%$ confidence interval 1.29 to 1.39$)$, male sex $(0.52,0.47$ to $0.58)$, previous hip fracture $(1.86,1.62$ to 2.14$)$, previous vertebral fracture $(1.71,1.31$ to 2.22$)$, other fracture $(1.45,1.35$ to 1.57$)$, baseline bisphosphonate use $(1.54,1.22$ to 1.92$)$, and baseline hormone replacement therapy $(0.69,0.63$ to 0.76$)$ contributed significantly to the risk of any fracture. Strongly statistically significant interaction terms were route of vitamin $\mathrm{D}$ administration $(\mathrm{P}=0.02)$, dosing interval $(\mathrm{P}=0.02)$, and co-administration of calcium $(\mathrm{P}=0.006)$, indicating significant modification of response to treatment (fig 2). Bisphosphonate use was of borderline significance $(\mathrm{P}=0.07)$. Previous fractures did not significantly interact with treatment response $(\mathrm{P}=0.64$ to 0.79 depending on site), nor did we find an interaction with age, sex, or hormone replacement therapy. As previous fractures did not modify the response, we included the Lyons study, which had no information on previous fractures, in the analysis. 
Table $1 \mid$ Characteristics of seven included clinical trials

\begin{tabular}{|c|c|c|c|c|c|c|c|c|}
\hline Trial & Patient category & $\begin{array}{l}\text { Randomisation* } \\
\text { and duration }\end{array}$ & Study arms & No & Mean (range) age & Men (\%) & $\begin{array}{l}\text { Previous fracture } \\
\text { (\%) }\end{array}$ & $\begin{array}{c}\text { Hormone therapy and } \\
\text { bisphosphonates } \\
\text { allowed }\end{array}$ \\
\hline Lyons $^{18}$ & $\begin{array}{l}\text { Residential home or } \\
\text { sheltered housing } \\
\text { residents (UK) }\end{array}$ & I; 36 months & $\begin{array}{c}\text { Oral } D_{2} 100000 \mathrm{IU} / 4 \text { months } \\
\text { v placebo }\end{array}$ & 3440 & $83.8(62-107)$ & 23.7 & ND & Yes \\
\hline Meyer $^{19}$ & $\begin{array}{l}\text { Nursing home } \\
\text { residents (Norway) }\end{array}$ & Q; 24 months & Oral $D_{3} 10 \mu \mathrm{g} /$ day $v$ placebo & 1144 & $84.7(47.6-101)$ & 24.1 & $\begin{array}{l}\text { Hip 26.2; vertebral } \\
\text { ND; other ND }\end{array}$ & Yes \\
\hline Porthouse ${ }^{21}$ & $\begin{array}{l}\text { General practice } \\
\text { patients with risk } \\
\text { factors (UK) }\end{array}$ & $\begin{array}{l}\text { I: } 18-42 \text { months } \\
\text { (median 22.5) }\end{array}$ & $\begin{array}{l}\text { Oral } D_{3} 20 \mu \mathrm{g} / \text { day }+1000 \mathrm{mg} \\
\text { calcium } v \text { leaflet }\end{array}$ & 3314 & $76.8(70.2-102.7)$ & 0 & $\begin{array}{l}\text { Hip } 0.5 \text {; vertebral } \\
0.8 \text {; other } 56.5\end{array}$ & Yes \\
\hline Larsen $^{24}$ & $\begin{array}{l}\text { Community dwelling } \\
\text { age } \geq 66 \text { (Denmark) }\end{array}$ & C; 42 months & $\begin{array}{c}\text { Oral } D_{3} 10 \mu \mathrm{g} / \text { day }+ \text { calcium } \\
1000 \mathrm{mg}+\text { environmental } \\
\text { intervention } v \text { oral } D_{3} 10 \mu \mathrm{g} / \text { day }+ \\
\text { calcium } 1000 \mathrm{mg} v \text { environmental } \\
\text { intervention } v \text { none }\end{array}$ & 9605 & $75(66-103)$ & 39.9 & $\begin{array}{c}\text { Hip 3.3; vertebral } \\
0.7 \text {; other } 7.4\end{array}$ & Yes \\
\hline RECORD ${ }^{22}$ & $\begin{array}{c}\text { Previous } \\
\text { osteoporotic fracture } \\
\text { (UK) }\end{array}$ & $\begin{array}{l}\text { I; 24-62 months } \\
\text { (median 30.4) }\end{array}$ & $\begin{array}{c}\text { Oral } D_{3} 20 \mu \mathrm{g} / \text { day }+ \text { calcium } \\
1000 \mathrm{mg} v \text { oral } \mathrm{D}_{3} 20 \mu \mathrm{g} / \text { day } v \\
\text { calcium } 1000 \mathrm{mg} v \text { double } \\
\text { placebo }\end{array}$ & 5292 & $77.5(70-100)$ & 15.3 & $\begin{array}{l}\text { Hip } 17.1 \text {; vertebral } \\
0.2 \text {; other } 82.8\end{array}$ & No \\
\hline Smith $^{20}$ & $\begin{array}{l}\text { General practice } \\
\text { patients presenting } \\
\text { for influenza } \\
\text { vaccination (UK) }\end{array}$ & $\begin{array}{l}\text { I: up to } 36 \text { months } \\
\text { (median 36.0) }\end{array}$ & $\begin{array}{c}\text { Intramuscular } D_{2} 300000 \mathrm{IU} / \\
12 \text { months } v \text { placebo }\end{array}$ & 9440 & $80.2(70.3-100.1)$ & 46.1 & $\begin{array}{c}\text { Hip 2.8; vertebral } \\
0.6 \text {; other } 34.8\end{array}$ & No \\
\hline WHI 23 & $\begin{array}{l}\text { Community based, } \\
\text { postmenopausal } \\
\text { women aged } \geq 50 \text { (US) }\end{array}$ & $\begin{array}{l}\text { I: median } 85 . \\
4 \text { months }\end{array}$ & $\begin{array}{c}\text { Oral } D_{3} 10 \mu \mathrm{g} / \text { day + calcium } \\
1000 \mathrm{mg} v \text { placebo }\end{array}$ & 36282 & $62.4(51-81)$ & None & $\begin{array}{l}\text { Hip } 0.6 \text {; vertebral } \\
1.5 \text {; other } 9.8\end{array}$ & Yes \\
\hline
\end{tabular}

Base model not including previous fractures (seven studies, $\mathrm{n}=68516$ )

Decade of age (hazard ratio $1.43,1.38$ to 1.48 ), male sex $(0.51,0.46$ to 0.56$)$, hormone replacement therapy $(0.65,0.60$ to 0.72$)$, and bisphosphonate use $(1.56,1.25$ to 1.95 ) contributed significantly to the risk of any fracture. Significant interaction terms were route $(\mathrm{P}=0.03)$ and calcium $(\mathrm{P}=0.04)$, and borderline significant interaction terms were bisphosphonate use $(\mathrm{P}=0.06)$ and interval (daily $v$ non-daily, $\mathrm{P}=0.12$ ).

Effect of vitamin D treatment (with or without calcium) Any fracture

The analysis covered 7202 fractures over 177203 person years. Placebo fracture rates were higher in the vitamin $\mathrm{D}$ trials than in the trials combining vitamin $\mathrm{D}$ with calcium, as these studies recruited older participants (table 1). We found no significant effect of vitamin D without calcium (hazard ratio $1.01,0.92$ to $1.12, \mathrm{P}=0.80$ ) (fig 3). Studies in which vitamin D was combined with calcium showed reduced fracture risk (hazard ratio 0.92 , 0.86 to $0.99, \mathrm{P}=0.025)$. We adjusted the analysis for study, age, and sex, as well as for baseline hormone replacement and bisphosphonate use. Stratification by route of administration showed a significant effect of oral vitamin $\mathrm{D}$ (hazard ratio $0.93,0.87$ to $0.99, \mathrm{P}=0.02$ ) but not injected vitamin $\mathrm{D}(1.11,0.95$ to $1.31, \mathrm{P}=0.20)$. Results were unaffected by exclusion of users of hormone replacement therapy and bisphosphonates. We found no significant treatment by study interaction in either group of studies (calcium and vitamin $\mathrm{D}$ studies $\mathrm{P}=0.67$ to 0.78 , vitamin $\mathrm{D}$ studies $\mathrm{P}=0.14$ to 0.44 ).

\section{Hip fracture}

In total, 978 hip fractures were recorded. The risk of hip fracture was borderline decreased by vitamin $\mathrm{D}$ with calcium (hazard ratio $0.84,0.70$ to $1.01, \mathrm{P}=0.07$ ) (fig 4). Vitamin D studies showed no reduction in risk of hip fracture $(1.09,0.92$ to $1.29, \mathrm{P}=0.34)$. Rates of hip fracture in the placebo group were lower in the calcium and vitamin $\mathrm{D}$ trials than in the vitamin $\mathrm{D}$ studies. Stratification by route showed treatment effects short of statistical significance (oral studies $0.93,0.81$ to 1.06 , $\mathrm{P}=0.26$; intramuscular studies $1.46,1.00$ to 2.13 , $\mathrm{P}=0.05)$. We found borderline significant treatment by study interaction terms for the RECORD study $(\mathrm{P}=0.06)$ and the Lyons study $(\mathrm{P}=0.09)$. This was driven by a hazard ratio for hip fracture with vitamin $\mathrm{D}$ of 0.98 (0.76 to 1.27$)$ in the Lyons study (pooled hazard ratio 1.18 (0.94 to 1.48$)$ in the other vitamin D studies) and a hazard ratio of 1.31 in the RECORD study (pooled hazard ratio 0.76 (0.62 to 0.94 ) for the remaining calcium and vitamin $\mathrm{D}$ studies).

\section{Clinical vertebral fracture}

Only 542 incident clinical vertebral fractures were reported. We found no significant treatment effect in calcium and vitamin D studies (hazard ratio 0.85, 0.66 to $1.11, \mathrm{P}=0.25)$ or vitamin $\mathrm{D}$ studies $(1.12,0.70$ to 1.79 , $\mathrm{P}=0.63)$ or when stratified by route of administration $(\mathrm{P}=0.27$ to 0.29$)$.

\section{Vitamin $D$ dose}

Irrespective of site of fracture or dose of vitamin D, we found no significant effect of vitamin D given without 

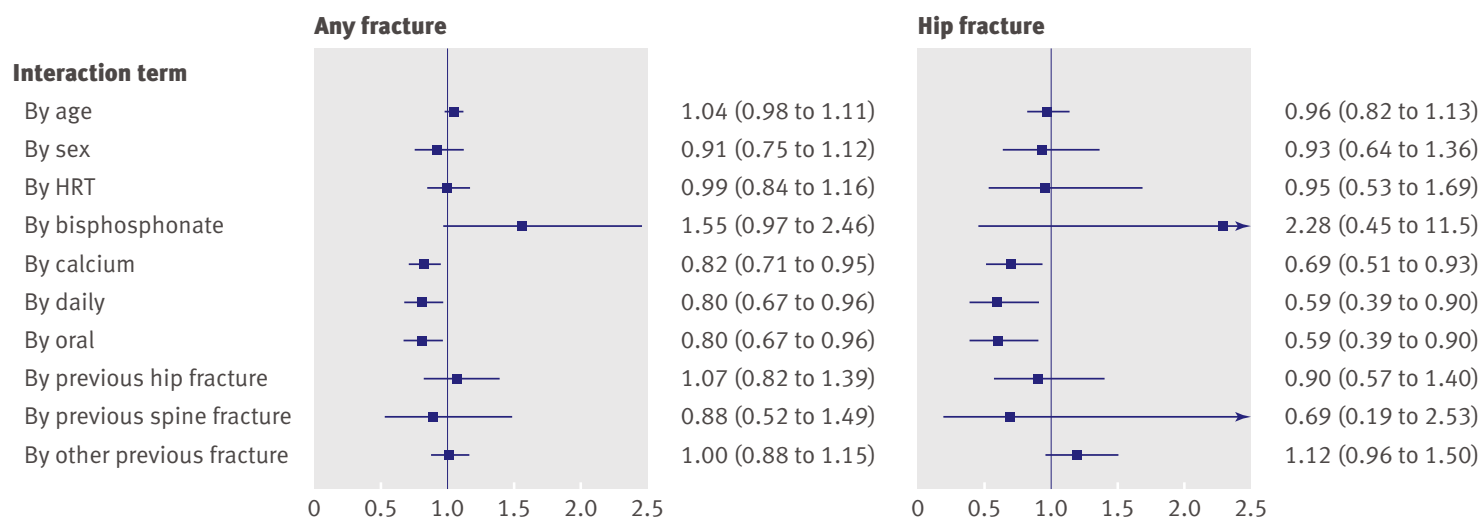

Fig 2 Interaction tests on logistic regression base model, 36 months intention to treat scenario. Each panel shows summary of 10 separate interaction analyses, testing statistical significance of each treatment by covariate interaction term added to base model. Coefficients differing significantly from 1.0 indicate presence of interaction (non-proportional hazards) between covariate and treatment; coefficients below 1.0 indicate greater treatment response (lower risk of fracture), and coefficients above 1.0 indicate smaller treatment response (higher risk of fracture). HRT=hormone replacement therapy

calcium. Vitamin D given as $10 \mu \mathrm{g}$ with calcium signifhip fracture $(\mathrm{P}<0.01)$. However, the $20 \mu \mathrm{g}$ dose with calcium was not associated with a reduced risk of fracture $(\mathrm{P}=0.58)$ (table 2).

\section{Absolute risk reduction and numbers needed to treat} We did this analysis only for vitamin D given with calcium, as vitamin $\mathrm{D}$ given alone could not be shown to reduce fracture risk significantly. For any fracture, calcium with vitamin $\mathrm{D}$ was associated with an absolute risk reduction of $0.5 \%$ over three years (untreated event rate 21.0 per 1000 person years, hazard ratio 0.92 ), corresponding to a number needed to treat of 213 people treated for three years to prevent a fracture. For people over the age of 70 , the absolute risk reduction was $0.9 \%$ (untreated event rate 29.0 per 1000 person icantly reduced the risk of any fracture $(\mathrm{P}<0.05)$ and years, hazard ratio 0.89 ) and the number needed to

treat was 111 . The corresponding numbers for people with previous fracture (untreated event rate 33.5 per 1000 person years, hazard ratio 0.87 ), irrespective of age, were $1.2 \%$ and 82 . For hip fractures specifically, the absolute risk reduction was $0.4 \%$ for participants aged over 70 and $0.2 \%$ in participants with previous fractures, giving numbers needed to treat of 255 and 548 .

\section{Sensitivity analysis}

In the influence analysis for vitamin $\mathrm{D}$ trials, the hazard ratio remained close to 1.0 irrespective of exclusion of any one study in both the any fracture scenario and the hip fracture scenario (fig 5). For calcium and vitamin D trials, the hip fracture analysis was sensitive to exclusion of contributing studies, leading to a mean effect close to 1.0 if the Larsen study was excluded. The corresponding any fracture analysis was robust, with mean hazard ratios indicating relatively little
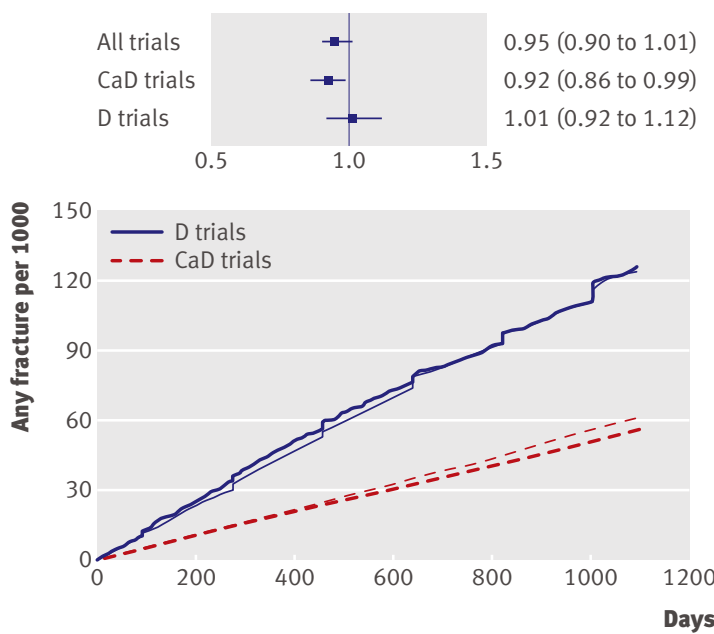

Fig 3 Cumulative fracture incidence for vitamin D (darker lines) and controls (lighter lines). Vitamin D and calcium studies and vitamin D studies are shown separately. Inset shows treatment effect and $95 \%$ confidence intervals. $\mathrm{CaD}=$ calcium and vitamin $\mathrm{D} ; \mathrm{D}=$ vitamin $\mathrm{D}$
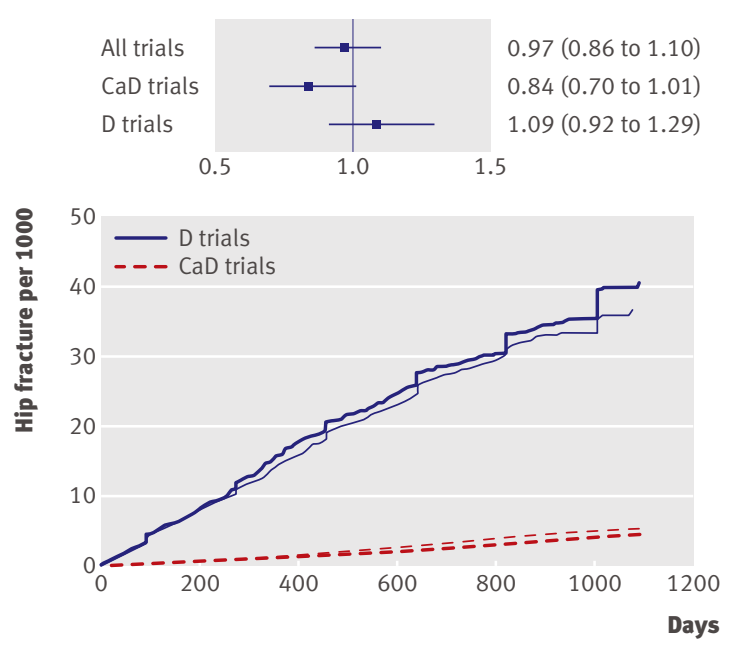

Fig 4 | Cumulative hip fracture incidence for vitamin D (darker lines) and controls (lighter lines). Vitamin D and calcium studies and vitamin D studies are shown separately. Inset shows treatment effect and $95 \%$ confidence intervals. $\mathrm{CaD}=$ calcium and vitamin $\mathrm{D} ; \mathrm{D}=$ vitamin $\mathrm{D}$ 
difference in effect on point estimates across calcium and vitamin $\mathrm{D}$ studies. The Larsen trial was unique in using a cluster randomised factorial design, in which environmental modification and drug review were added in two study arms. We repeated the hip fracture analysis across the calcium and vitamin D studies excluding the two arms of the Larsen study that included environmental intervention. In this post hoc analysis, the effect of calcium and vitamin D on hip fractures had a hazard ratio of 0.82 (0.67 to 0.99 , $\mathrm{P}=0.045)$. For vitamin $\mathrm{D}$ studies, mean effects were between 1.00 (exclusion of Smith study) and 1.18 (exclusion of Lyons study). Considering $20 \mu \mathrm{g}$ of ergocalciferol to be equivalent to $10 \mu \mathrm{g}$ rather than $20 \mu \mathrm{g}$ of cholecalciferol affected only the vitamin D studies. This did not alter the findings (any fracture: hazard ratio $1.01,0.90$ to $1.14, \mathrm{P}=0.83$ for lower dose and $1.01,0.82$ to $1.24, \mathrm{P}=0.95$ for higher dose).

Trials by Chapuy, Lips, Trivedi, and Law and colleagues did not contribute data to our analysis but reported similar effects. ${ }^{915-17}$ Inclusion of summary data from these studies led to a combined hazard ratio for hip fracture of 1.11 (0.96 to 1.29) for vitamin $\mathrm{D}$ studies and 0.82 (0.72 to 0.95$)$ for calcium and vitamin D studies.

\section{DISCUSSION}

This analysis of individual patients' data from seven large fracture trials indicates that vitamin $\mathrm{D}$ with calcium reduces the overall risk of fracture, and probably hip and clinical vertebral fractures, irrespective of sex and fracture history. For hip fractures, we were able to show a significant risk reduction with the lower vitamin $\mathrm{D}$ dose of $10 \mu \mathrm{g}$ daily given with calcium. Because the reduction in risk was small ( $16 \%$ or less) and rates of fracture were low in most studies, the number needed to treat ranged from more than 200 people (no previous fracture) to 82 people (with a previous fracture) treated for three years to prevent any fracture and from 548 (no previous fracture) to 255 people (with a previous fracture) treated for three years to prevent a hip fracture. Vitamin $\mathrm{D}$ given alone in daily doses of $10-20 \mu \mathrm{g}(400-800 \mathrm{IU})$ was not shown to be effective.

\section{Comparisons with other studies}

Our results agree with three recent meta-analyses that examined study level data from trials of supplementation with vitamin $\mathrm{D}$, calcium, or the two combined. ${ }^{121326}$ The trials included in these systematic reviews differed slightly. Two reviews focused on vitamin D and also found that vitamin $\mathrm{D}$ alone was ineffective in preventing any fracture or hip fractures and that the combination of calcium and vitamin D showed benefit. ${ }^{12}{ }^{13}$ Boonen et al did not examine "any fractures"12; in the Cochrane review, calcium and vitamin D prevented any fractures only in people living in institutions. ${ }^{13}$ By contrast, the findings of our individual patient data review strongly favoured calcium and vitamin D for prevention of any fractures in all populations examined. The Cochrane review did not find that clinical vertebral fracture was prevented by vitamin $\mathrm{D}$ with or without calcium supplementation, ${ }^{13}$ as found here, although few trials provided these data. These two previous systematic reviews did not assess the influence of dose of vitamin D or compare ergocalciferol with cholecalciferol in detail.

Tang et al systematically reviewed fracture prevention in trials of calcium, with and without vitamin D. ${ }^{26}$ The overall risk reduction reported was 0.90 (95\% confidence interval 0.80 to 1.00$)$ for calcium trials and 0.97 (0.92 to 1.03) for calcium and vitamin D trials, although no significant difference was found between these two groups. The group of calcium and vitamin D trials in Tang et al differed from those in the Cochrane review and the review by Boonen et al and included Larsen, ${ }^{24}$ without taking account of the cluster design.

Recently, Bischoff-Ferrari and colleagues did a new study level meta-analysis covering 12 randomised controlled trials and concluded that received vitamin D doses in excess of $400 \mathrm{IU} /$ day prevented non-vertebral fractures. ${ }^{27}$ Differences between their conclusions and ours, although pronounced, are explained by the classification of the WHI study (400 IU/10 $\mu \mathrm{g}$ vitamin D plus calcium) as a high dose (765 IU/19 $\mu \mathrm{g})$ study by including other vitamin $\mathrm{D}$ sources in the treatment arm (intervention 400 IU plus base 365 IU) and disregarding them in the control arm (intervention 0 IU plus base 368 IU).

\begin{tabular}{|c|c|c|}
\hline Fracture & $10 \mu \mathrm{g}$ dose & $20 \mu \mathrm{g}$ dose \\
\hline With calcium: & (WHI, Larsen studies) & (Porthouse, RECORD-2 studies) \\
\hline Any & $\begin{array}{l}\text { Treated } 18.7 / 1000 \mathrm{PY} \text {; untreated } 20.2 / 1000 \mathrm{PY} ; \mathrm{HR}=0.91(95 \% \mathrm{Cl} 0.85 \text { to } \\
0.99), \mathrm{P}=0.02\end{array}$ & Treated 43.2/1000 PY; untreated 51.1/1000 PY; HR 0.95 (0.80 to 1.14), P=0.58 \\
\hline Hip & $\begin{array}{l}\text { Treated 2.4/1000 PY; untreated 3.0/1000 PY; HR=0.74 (0.60 to 0.91), } \\
\mathrm{P}=0.005\end{array}$ & Treated 10.3/1000 PY; untreated 9.2/1000 PY; HR 1.30 (0.88 to 1.92), $\mathrm{P}=0.19$ \\
\hline Vertebral & Treated 1.4/1000 PY; untreated 1.6/1000 PY; HR=0.86 (0.65 to 1.14), P=0.31 & Treated 2.7/1000 PY; untreated 3.1/1000 PY; HR 0.97 (0.48 to 1.98), $\mathrm{P}=0.93$ \\
\hline Without calcium: & (Meyer study) & (Lyons, Smith, RECORD-1 studies) \\
\hline Any & $\begin{array}{l}\text { Treated 85.9/1000 PY; untreated 94.1/1000 PY; HR=0.93 (0.67 to 1.28), } \\
\mathrm{P}=0.64\end{array}$ & Treated 45.9/1000 PY; untreated 44.4/1000 PY; HR 1.02 (0.92 to 1.14), $\mathrm{P}=0.69$ \\
\hline Hip & $\begin{array}{l}\text { Treated } 61.3 / 1000 \text { PY; untreated 56.2/1000 PY; HR=1.10 (0.74 to 1.64), } \\
P=0.64\end{array}$ & Treated 14.0/1000 PY; untreated 13.0/1000 PY; HR 1.08 (0.89 to 1.30), P=0.45 \\
\hline Vertebral & NA & Treated 2.4/1000 PY; untreated 2.1/1000 PY; HR 1.10 (0.69 to 1.76), $\mathrm{P}=0.68$ \\
\hline
\end{tabular}




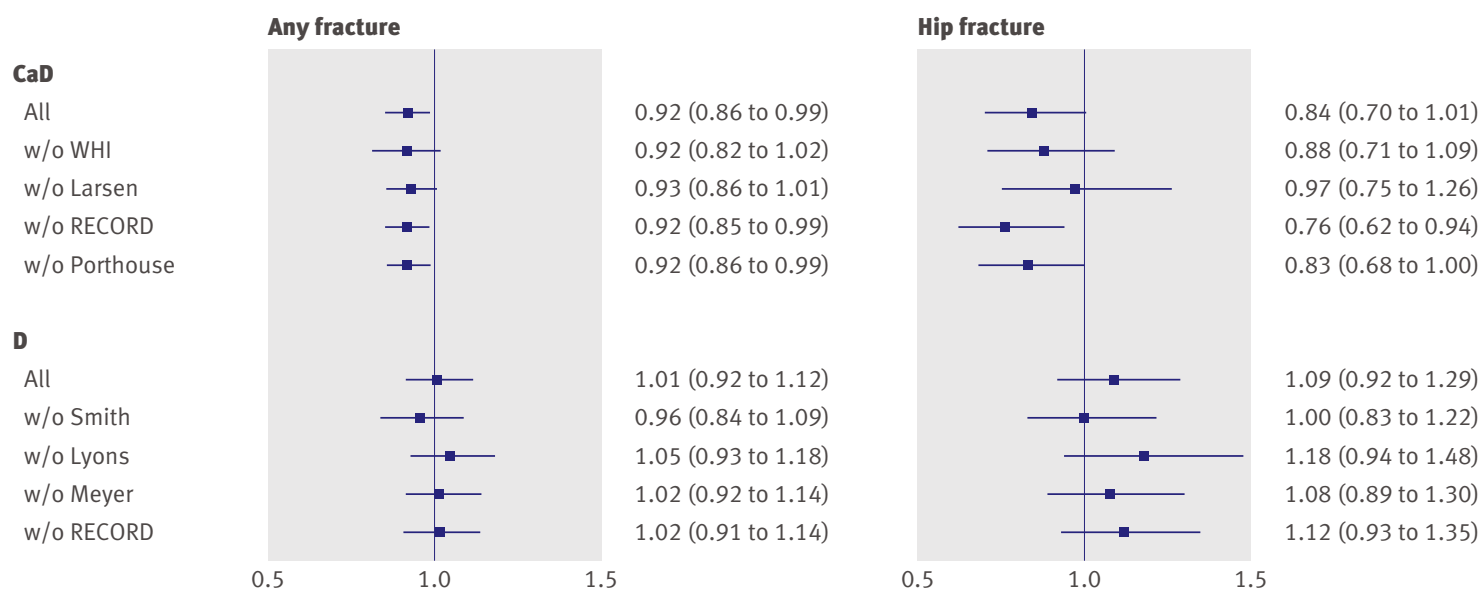

Fig 5 Sensitivity analysis: influence of removing individual studies from analysis. $C a D=$ calcium and vitamin $D$ trials; $D=v i t a m i n$ D trials; w/o=without

Whether calcium is more important in preventing fractures than was previously recognised remains to be determined. An individual patient data meta-analysis is being done on this topic (Mark Bolland, personal communication, 2009). Calcium and vitamin D are likely to be more effective in attenuating secondary hyperparathyroidism, and thus bone turnover and bone loss, than is vitamin D alone. ${ }^{228}$ Higher doses of vitamin $\mathrm{D}$ than were used in the existing trials may be needed to suppress bone turnover if calcium is not co-administered. ${ }^{29}$ We did not have information related to baseline vitamin D (diet, sunlight, and supplements) and calcium intake. In most of the included studies, serum vitamin $\mathrm{D}$ was measured only in small subgroups. Wide variations are likely, owing to international differences in food fortification and differences in the age and mobility of study populations. Previous reports of protective effects of calcium and vitamin $D$ supplementation in institutionalised populations and lack of effect in non-institutionalised populations suggest that such differences strongly modify the anti-fracture efficacy of calcium with vitamin D. ${ }^{915}$

Within the vitamin $\mathrm{D}$ with calcium trials, only the lower vitamin $\mathrm{D}$ dose (10 $\mu \mathrm{g}$ daily) produced a reduction in hip fracture risk. This is not evidence that a $20 \mu \mathrm{g}$ daily dose is inferior to a $10 \mu \mathrm{g}$ daily dose but may reflect the fact that the trials of $20 \mu \mathrm{g}$ vitamin D with calcium attempted to provide fracture prevention at a threefold higher risk level for hip fractures than did studies using the lower dose (table 2). Thus, our recommendation would be to use a vitamin $\mathrm{D}$ dose of at least $10 \mu \mathrm{g}$ (400 IU) daily combined with $1000 \mathrm{mg}$ of calcium. In high risk patients, this should be supplemented by bisphosphonates or other anti-osteoporotic drugs in accordance with national and international guidelines.

\section{Strengths and limitations}

We were unable to obtain data for four of the 11 identified studies that fulfilled the inclusion criteria. Our findings support and further substantiate previous meta-analyses of study level data that included these studies. ${ }^{11326}$ The results of our analysis were robust in effect size and direction to the exclusion of very large contributing studies.

We restricted the analysis to 36 months, as only the WHI study was of materially longer duration. With our current knowledge on reversal of secondary hyperparathyroidism, this time frame seems reasonable

The lack of anti-fracture efficacy seen in the Smith trial has been suggested to be due to low bioavailability of the preparation. ${ }^{20}$ However, although removing this study from the analysis (fig 5) nominally changed the anti-fracture effect of the vitamin D only studies from a small increase to a small decrease in risk, both results failed to achieve statistical significance.

We could not obtain sufficient information about compliance to do a per protocol analysis. The effect size should thus be considered as worst case. We had, however, pre-specified an intention to treat analysis as the primary hypothesis test for this study, allowing the effect size of this intervention to be compared with the effect sizes of interventions such as prevention of falls and anti-resorptive drugs.

The Larsen trial was very influential in the analysis for hip fracture but differed greatly from other studies in design by being randomised only at the level of home care districts and by using a factorial design that included drug review, leaflets, and other environmental interventions. ${ }^{24}$ As we had access to patient level information, we were able to repeat the hip fracture analyses without the environmental intervention arms. However, the calcium and vitamin D arm still differed from the untreated arm in having the offer of a drug review. Removing the environmental arms of the Larsen study did not alter the effect size of the joint analysis.

Only a single study - the Meyer study-provided data for vitamin $\mathrm{D}$ given alone at the lower dose. The biological equivalence of ergocalciferol and cholecalciferol doses remains controversial. ${ }^{25}$ Results, however, were similar whether the potency of ergocalciferol was considered to be $100 \%$ or $50 \%$ of that of cholecalciferol. Whether intermittent dosing 


\section{WHAT IS ALREADY KNOWN ON THIS TOPIC}

A rationale exists for the use of vitamin $D$ to prevent fractures in older people

What dose of vitamin $D$ is needed for prevention of fractures is unclear, as is whether daily calcium co-supplementation is needed

\section{WHAT THIS STUDY ADDS}

Vitamin D alone in doses equivalent to $10-20 \mu \mathrm{g} /$ day is not effective in fracture prevention

Co-administration of $1000 \mathrm{mg}$ calcium/day is required for fracture prevention

Fracture prevention is found across a wide age range, irrespective of sex and fracture history

can be equated with an average daily dose for vitamin $\mathrm{D}$ remains unresolved. Additional studies would be needed to clarify whether the failure of standalone vitamin $\mathrm{D}$ in preventing fractures is due to the route of administration, the long time interval between doses, the nature of the vitamin $\mathrm{D}$ preparation, or the propensity for studies of vitamin D to enrol participants of higher age and greater fracture risk than do studies of calcium and vitamin D. Although our analysis did not provide support for any interaction with age or fracture history, we cannot distinguish between effects of compound, route, and regimen, as studies of intramuscular administration never used daily dosing, whereas calcium and vitamin D studies always used oral administration and invariably used daily dosing.

We had to make allowance for differences between studies in available parameters - for example, no data on fracture history were available in the Lyons study, ${ }^{18}$ and no data on incident clinical vertebral fractures were available in the Meyer study. ${ }^{19}$ We saw no interaction, however, between treatment effect and fracture history in six studies with available data. Studying adverse events was beyond the scope of this analysis and would have been difficult to interpret, as the method of tracking differed more widely between studies than did reporting of fracture outcomes.

The important strength of this analysis is that we were able to calculate absolute fracture rates and treatment effects across a wide range of study participants and interventions, adjust effects for previous fractures and for the use of bisphosphonates and hormone replacement therapy at the level of the individual participant, account for interactions and study heterogeneity, and further substantiate the conclusions of nonindividual patient data meta-analyses.

\section{Conclusions and policy implications}

Daily calcium and vitamin D supplementation, even at doses as low as $10 \mu \mathrm{g}$ of vitamin D daily, significantly reduces the risk of fracture, with incidence curves deviating after about 16 months. Fracture prevention seemed to be homogeneous across a wide age range and was unmodified by fracture history or sex. We must emphasise that this analysis does not allow for a direct comparison of vitamin $\mathrm{D}$ against vitamin $\mathrm{D}$ given with calcium, but only comparisons between each intervention and no treatment. Whether intermittent doses of vitamin $\mathrm{D}$ given without calcium supplements can reduce the risk of fractures remains unresolved from the studies in this analysis. Additional studies of vitamin D are also needed, especially trials of vitamin $\mathrm{D}$ given daily at higher doses without calcium.

We are grateful to the authors of the original trial reports: G B Smedshaug, E Kvaavik, J A Falch, A Tverdal, J I Pedersen, H Raphael, P Maslin, S Crozier, E R Larsen, A Foldspang, A M Grant, M K Campbell, A M McDonald, G S MacLennan, G C McPherson, C Donaldson, W J Gillespie, C M J Robinson, W A Wallace, M Gass, R B Wallace, C E Lewis, T Bassford, S A Beresford, H R Black, P Blanchette, D E Bonds, R L Brunner, R G Brzyski, B Caan, J A Cauley, R T Chlebowski, S R Cummings, I Granek, J Hays, G Heiss, S L Hendrix, B V Howard, J Hsia, F A Hubbell, K C Johnson, H Judd, J M Kotchen, L H Kuller, R D Langer, N L Lasser, M C Limacher, S Ludlam, J E Manson, K L Margolis, J McGowan, J K Ockene, M J O'Sullivan, L Phillips, R L Prentice, G E Sarto, M L Stefanick, L Van Horn, E Whitlock, G L Anderson, A R Assaf, D Barad, R A Lyons, S Brophy, R G Newcombe, C J Phillips, B Lervy, R Evans, M D Stone, K Wareham, J Porthouse, S Cockayne, C King, L Saxon, E Steele, T Aspray, M Baverstock, Y Birks, J Dumville, C Iglesias, S Puffer, A Sutcliffe, and I Watt. We thank the WHI investigators and staff for their dedication and the study participants for making the programme possible. A full listing of WHI investigators can be found at www.whiscience.org/publications/ WHI_investigators_shortlist.pdf

DIPART Group: B Abrahamsen, professor, Department of Medicine F, Copenhagen University Hospital Gentofte, Hellerup, and Institute of Clinical Research, University of Southern Denmark, Odense, Denmark; T Masud, professor, Geriatric Medicine, Nottingham University Hospitals, Nottingham; A Avenell, clinical senior lecturer, Health Services Research Unit, University of Aberdeen, Aberdeen; F Anderson, clinical senior lecturer, Geriatric Medicine, DOHaD Research Division, University of Southampton School of Medicine, Southampton; H E Meyer, professor, Division of Epidemiology, Norwegian Institute of Public Health, and Section for Preventive Medicine and Epidemiology, Oslo University of Oslo, Oslo, Norway; C Cooper, professor, MRC Epidemiology Resource Centre, Southampton; H Smith, professor, Public Health and Primary Care, Brighton and Sussex Medical School, Brighton; A Z LaCroix, professor, Public Health, Fred Hutchinson CRC, Seattle, WA, USA; D Torgerson, professor, York Trials Unit, University of York, York; A Johansen, consultant, Department of Public Health, Swansea University, Swansea, and Academic Department of Geriatric Medicine, University Hospital of Wales, Cardiff; R Jackson, professor, Endocrinology, Ohio State University, Columbus, OH, USA; L Rejnmark, staff specialist, Endocrinology, Aarhus University Hospital, Aarhus, Denmark; J Wactawski-Wende, professor, Departments of Social and Preventive Medicine and Gynecology-Obstetrics, University at Buffalo, Buffalo, NY, USA; K Brixen, clinical associate professor, Institute of Clinical Research, University of Southern Denmark, Odense, and Endocrinology, Odense University Hospital, Odense, Denmark; L Mosekilde, professor, Endocrinology, Aarhus University Hospital; J A Robbins, professor, Internal Medicine, University of California at Sacramento, CA, USA; R M Francis, professor, Geriatric Medicine, Freeman Hospital, Newcastle. Contributors: BA, TM, KB, JAR, LM, and RMF conceived and designed this joint analysis. BA and $L R$ acquired and analysed the data. BA, TM, AA, HS, LR, JWW, KB, JAR, LM, and RMF drafted the article. All members of the DIPART Group contributed to revising the manuscript critically and approved the final version, as well as contributing to the interpretation of the joint results and to the design of their individual trials. BA is the guarantor.

Funding: The WHI program is funded by the National Heart, Lung, and Blood Institute, National Institutes of Health, US Department of Health and Human Services through contracts N01WH22110, 24152, 32100-2, 32105-6, 32108-9, 32111-13, 32115, 32118-32119, 32122, 42107-26, 42129-32, and 44221. AA acknowledges personal funding from the UK Medical Research Council and Chief Scientist Office of the Scottish Government Health Directorates.

Competing interests: BA receives consulting fees from Novartis, serves on advisory boards for Amgen and Nycomed, and receives lecture fees from Eli Lilly and Procter \& Gamble. TM receives research funding and speakers' fees from Merck, Procter \& Gamble, Roche, Eli Lilly, Shire, ProStrakan, and Servier. FA has received honorariums for lectures and advisory panels from Shire, Celltech, ProStrakan, and Merck. CC has served in a consultant capacity to the Alliance for Better Bone Health, Eli Lilly, Merck Sharp \& Dohme, Amgen, GlaxoSmithKline, Roche, and Servier. DT has received research funding from Shire Pharmaceuticals. ALC serves on advisory boards for studies funded by Pfizer, Procter \& 
Gamble, and Sanofi-Aventis. KB has received consultancy fees from Servier, Novartis, Eli Lilly, Nycomed, and Osteologix, as well as speakers' fees from Eli Lilly, Novartis, and Servier and research grants from Merck Sharp \& Dohme. RMF has served as an adviser to Procter \& Gamble, Sanofi, Merck Sharp \& Dohme, Roche, GlaxoSmithKline, Novartis, Lilly, Servier, Nycomed, Shire, and Prostrakan.

Ethical approval: Not needed.

Data sharing: Varies by trial; please contact study leads of primary trials

1 Johansen A, Evans RJ, Stone MD, Richmond PW, Lo SV, Woodhouse KW. Fracture incidence in England and Wales: a study based on the population of Cardiff. Injury 1997;28:655-60.

2 Holroyd C, Cooper C, Dennison E. Epidemiology of osteoporosis. Bes Pract Res Clin Endocrinol Metab 2008;22:671-85.

3 Brennan SJ, Johansen A, Butler J, Stone M, Richmond P, Jones S, et al. Place of residence and risk of fracture in older people: a populationbased study of over 65-year-olds in Cardiff. Osteoporos Int 2003;14:515-9.

4 Aspray TJ, Stevenson P, Abdy SE, Rawlings DJ, Holland T, Francis RM. Low bone mineral density measurements in care home residents-a treatable cause of fractures. Age Ageing 2006;35:37-41.

5 Holick MF. Vitamin D deficiency. N Engl J Med 2007;357:266-81.

6 Hirani V, Primatesta P. Vitamin D concentrations among people aged 65 years and over living in private households and institutions in England: population survey. Age Ageing 2005;34:485-91.

7 Lips P. Vitamin D deficiency and secondary hyperparathyroidism in the elderly: consequences for bone loss and fractures and therapeutic implications. Endocr Rev 2001;22:477-501.

8 Bischoff-Ferrari HA, Giovannucci E, Willett WC, Dietrich T, Dawson-Hughes B. Estimation of optimal serum concentrations of 25-hydroxyvitamin D for multiple health outcomes. Am J Clin Nutr 2006;84:18-28.

9 Chapuy MC, Arlot ME, Duboeuf F, Brun J, Crouzet B, Arnaud S, et al. Vitamin D3 and calcium to prevent hip fractures in the elderly women. N EnglJ Med 1992;327:1637-42.

10 Francis RM, Anderson FH, Patel S, Sahota O, van Staa TP. Calcium and vitamin $D$ in the prevention of osteoporotic fractures. $Q / M$ 2006;99:355-63.

11 Bischoff-Ferrari HA, Willett WC, Wong JB, Giovannucci E, Dietrich T, Dawson-Hughes B. Fracture prevention with vitamin D

supplementation: a meta-analysis of randomized controlled trials. JAMA 2005;293:2257-64.

12 Boonen S, Lips P, Bouillon R, Bischoff-Ferrari HA, Vanderschueren D, Haentjens P. Need for additional calcium to reduce the risk of hip fracture with vitamin d supplementation: evidence from a comparative metaanalysis of randomized controlled trials. J Clin Endocrinol Metab 2007;92:1415-23.

13 Avenell A, Gillespie WJ, Gillespie LD, and O'Connell D. Vitamin D and vitamin $\mathrm{D}$ analogues for preventing fractures associated with involutional and post-menopausal osteoporosis. Cochrane Database Syst Rev 2009;(3):CD000227.

14 Lambert PC, Sutton AJ, Abrams KR, Jones DR. A comparison of summary patient-level covariates in meta-regression with individual patient data meta-analysis. J Clin Epidemiol 2002;55:86-94.

15 Lips P, Graafmans WC, Ooms ME, Bezemer PD, Bouter LM. Vitamin D supplementation and fracture incidence in elderly persons: a randomized, placebo-controlled clinical trial. Ann Intern Med 1996;124:400-6.
16 Trivedi DP, Doll R, Khaw KT. Effect of four monthly oral vitamin D3 (cholecalciferol) supplementation on fractures and mortality in men and women living in the community: randomised double blind controlled trial. BMJ 2003;326:469.

17 Law M, Withers H, Morris J, Anderson F. Vitamin D supplementation and the prevention of fractures and falls: results of a randomised trial in elderly people in residential accommodation. Age Ageing 2006;35:482-6

18 Lyons RA, Johansen A, Brophy S, Newcombe RG, Phillips CJ, Lervy B et al. Preventing fractures among older people living in institutional care: a pragmatic randomised double blind placebo controlled trial of vitamin D supplementation. Osteoporos Int 2007;18:811-8.

19 Meyer HE, Smedshaug GB, Kvaavik E, Falch JA, Tverdal A, Pedersen II. Can vitamin $D$ supplementation reduce the risk of fracture in the elderly? A randomized controlled trial. J Bone Miner Res 2002;17:709-15.

20 Smith H, Anderson F, Raphael H, Maslin P, Crozier S, Cooper C. Effect of annual intramuscular vitamin $\mathrm{D}$ on fracture risk in elderly men and women-a population-based, randomized, double-blind, placebocontrolled trial. Rheumatology 2007;46:1852-7.

21 Porthouse J, Cockayne S, King C, Saxon L, Steele E, Aspray T, et al. Randomised controlled trial of calcium and supplementation with cholecalciferol (vitamin D3) for prevention of fractures in primary care. BMJ 2005;330:1003.

22 Grant AM, Avenell A, Campbell MK, McDonald AM, MacLennan GS, McPherson GC, et al. Oral vitamin D3 and calcium for secondary prevention of low-trauma fractures in elderly people (Randomised Evaluation of Calcium Or vitamin D, RECORD): a randomised placebocontrolled trial. Lancet 2005;365:1621-8.

23 Jackson RD, LaCroix AZ, Gass M, Wallace RB, Robbins J, Lewis CE, et al. Calcium plus vitamin D supplementation and the risk of fractures. N Engl J Med 2006;354:669-83.

24 Larsen ER, Mosekilde L, Foldspang A. Vitamin D and calcium supplementation prevents osteoporotic fractures in elderly community dwelling residents: a pragmatic population-based 3-yea intervention study. J Bone Miner Res 2004;19:370-8.

25 Romagnoli E, Mascia ML, Cipriani C, Fassino V, Mazzei F, D’Erasmo E, et al. Short and long-term variations in serum calciotropic hormones after a single very large dose of ergocalciferol (vitamin D2) or cholecalciferol (vitamin D3) in the elderly. J Clin Endocrinol Metab 2008;93:3015-20.

26 Tang BM, Eslick GD, Nowson C, Smith C, Bensoussan A. Use of calcium or calcium in combination with vitamin D supplementation to prevent fractures and bone loss in people aged 50 years and older: a meta-analysis. Lancet 2007;370:657-66.

27 Bischoff-Ferrari HA, Willett WC, Wong JB, Stuck AE, Staehelin HB, Orav EJ, et al. Prevention of nonvertebral fractures with oral vitamin and dose dependency: a meta-analysis of randomized controlled trials. Arch Intern Med 2009 23;169:551-61.

28 Harwood RH, Sahota O, Gaynor K, Masud T, Hosking DJ. A randomised, controlled comparison of different calcium and vitamin D supplementation regimens in elderly women after hip fracture: the Nottingham Neck of Femur (NONOF) study. Age Ageing 2004;33:45-51

29 Aloia JF, Patel M, Dimaano R, Li-Ng M, Talwar SA, Mikhail M, et al. Vitamin $D$ intake to attain a desired serum 25 -hydroxyvitamin D concentration. Am J Clin Nutr 2008;87:1952-8.

Accepted: 23 October 2009 